\title{
A ANPHLAC e as perspectivas e potencialidades do uso da internet para o desenvolvimento e divulgação dos estudos sobre a História das Américas no Brasil
}

\author{
Antonio Carlos Amador Gil*
}

\section{Introdução}

Com o avanço da informatização e a disseminação do uso da internet, várias questões se colocam para o historiador, dentre elas, o acesso a estas novas tecnologias e suas utilizações no intuito de potencializar as atividades no âmbito da pesquisa e do ensino da história das Américas.

Pretendemos, neste artigo, fazer um relato do uso da internet pela ANPHLAC desde finais dos anos de 1990. O site da ANPHLAC tem desenvolvido o trabalho de divulgação da história das Américas através da disponibilização de diversos conteúdos e da administração de uma lista de discussão.

Almejamos, a partir desta experiência, ressaltar os aspectos que são importantes e as perspectivas e potencialidades para o desenvolvimento da pesquisa e do ensino de história das Américas no Brasil.

\section{A questão do acesso}

Quanto ao acesso, é interessante o cenário que Umberto Eco desenhava em meados dos anos de 1990:

\begin{abstract}
O pior cenário que podemos imaginar é uma sociedade dividida em três categorias. No nível mais baixo estaria uma classe trabalhadora sem possibilidade de usar os computadores e desinteressada dos livros, dependendo totalmente da comunicação audiovisual oferecida pela televisão. Em seguida estaria uma classe média com possibilidade de usar computadores somente para suas necessidades específicas e diárias. E em cima estaria uma "nomenklatura" (na acepção soviética do termo), que sabe como trabalham as máquinas e os programas e que é capaz de distinguir entre a informação interessante e a inútil. ${ }^{1}$
\end{abstract}

Umberto Eco coloca como principal problema de nossa sociedade, encontrar uma forma de criar uma "mass-nomenklatura", processo que ocorreu com a imprensa. Isto era uma discussão muito forte naqueles anos. A questão do acesso era um dos

\footnotetext{
* Prof. Associado III da Universidade Federal do Espírito Santo (UFES). Pós-Doutor em História da América. E-mail: antonio.gil@ufes.br

${ }^{1}$ Umberto Eco pondera os efeitos sociais das tecnologias de informação: ECO, Umberto. OEP/ Office Equipment \& Products. Winchester, MA, v.25, n.208, p.48, jan. 1996. (Tradução nossa) 
problemas discutidos, pois a maioria ainda não tinha acesso a estas novas tecnologias. Naqueles anos, por exemplo, na Itália, existia um computador conectado à internet para cada 1.800 habitantes, na Alemanha esta relação era de 1 conexão a cada 380 habitantes. O acesso no Brasil era muito mais reduzido. Segundo os dados da Pesquisa Nacional por Amostra de Domicílio (PNAD)/IBGE de 2003, só 11\% das casas do país estavam conectadas à internet. Hoje em dia, com a popularização da internet, o surgimento dos smartphones, etc, houve um considerável aumento do acesso, mas devemos sempre estar atentos aos índices ainda muito baixos de acesso dos países que concentram a maioria dos pobres em nosso mundo contemporâneo, inclusive na América Latina. Segundo o PNAD/IBGE de 2008, somente 31,2\% das residências brasileiras possuíam microcomputador e $23,8 \%$ estavam conectadas à internet. Não podemos deixar de frisar as disparidades regionais, na região sudeste, 31,5\% dos domicílios em 2008 estavam conectados, todavia, apenas 10,6\% das residências da região norte estavam conectadas à internet. Dados de 2009 informam que 67,5 milhões de brasileiros acessavam a internet de quaisquer meios (35,5\% da população na época). No final de 2010, o acesso chegou a 73,9 milhões de brasileiros. Segundo dados do IBGE do início de 2012, aproximadamente 43\% dos brasileiros têm acesso à internet. Estes dados mostram o grande processo de inclusão digital nos últimos anos, mas ainda temos muitas pessoas e domicílios sem acesso digital. Os dados em relação às escolas são profundamente preocupantes. Segundo o resumo técnico do Censo Escolar do INEP, realizado em 2011, 42,6\% das escolas de ensino fundamental têm acesso à internet e 55,9\% das instituições não têm laboratórios de informática. Vemos, portanto, que apesar do avanço do uso da internet, ainda temos um caminho longo até alcançarmos a universalização do acesso.

A ANPHLAC, que surgiu no início dos anos de 1990, colocou em pauta a necessidade de criar veículos de acesso à informação através da internet, durante a gestão que iniciou suas atividades em 1998. Nesta gestão, assumi o cargo de segundo secretário e propus a criação de uma home page que disponibilizaria conteúdos e informações referentes à história de nossas Américas, principalmente a história latinoamericana.

Em 1998 tínhamos um grande desafio. Naquele momento, a questão do acesso à internet era um grande problema, visto que poucos brasileiros possuíam computadores 
ligados à internet, e os que possuíam acesso, geralmente o faziam via linha discada. A comunidade universitária começava a ter maior acesso dentro dos campi universitários. Contudo, mesmo no meio acadêmico, ainda havia poucos laboratórios de informática e nem toda a comunidade tinha pleno acesso a estes serviços. O problema financeiro era então um dos pontos mais sensíveis, pois os custos de equipamentos e de softwares eram proibitivos. Outro problema que restringia o seu uso por uma parte da população, era o predomínio da língua inglesa. Apesar de existirem várias instituições que disponibilizavam o acesso em português, a maioria das páginas eletrônicas e locais de interesse para os historiadores e estudantes de história se encontrava disponível majoritariamente em inglês, o que restringia o seu acesso, pelo menos, aos estudantes que não dominavam a língua inglesa.

Quais eram as possibilidades de desenvolvimento da internet naquele momento? Creio que, mesmo agora, não podemos traçar ainda o seu desenvolvimento futuro. Porém concordamos com as afirmações de Umberto Eco: "estas tecnologias existem e não há caminho de regresso. Os meios eletrônicos representam um estímulo e um suplemento aos livros e à leitura". Outra questão que se coloca é a grande quantidade de informação disponível atualmente através das tecnologias eletrônicas. A abundância de informação é um risco. Não há diferença entre ter dezenas, milhares ou milhões de gigabytes de informação armazenados em computadores ou não ter nenhum bit. Isto porque a informação necessita ser consumida bit a bit. A tecnologia ainda não conseguiu alterar o tempo necessário para adquirir a informação, ou seja, lê-la e entendê-la.

A quantidade não é o único aspecto do problema. Outro aspecto é a qualidade. Navegar na internet pode significar, também, viajar por montanhas de lixo sem nenhum interesse. Isto ocorre principalmente quando se navega sem rumo, mas não é o caso quando se navega a partir de endereços reconhecidamente de interesse nas áreas específicas de conhecimento.

O trabalho do historiador continua se baseando na leitura de documentação nos arquivos e na leitura de bibliografia especializada. Contudo, a internet tem criado novas possibilidades que têm ajudado o desenvolvimento do trabalho de pesquisa dos historiadores. 
Através da internet, o historiador que pesquisa os temas de história latinoamericana e das Américas, em geral, pode consultar as diversas bibliotecas que tenham seus acervos informatizados e que estejam conectados à rede. Até recentemente, o acesso era restrito à coleta de referências bibliográficas. Este acesso era e continua sendo de grande importância, principalmente se o historiador mora em localidades distantes das bibliotecas. As dificuldades financeiras geralmente impedem viagens para levantamento bibliográfico, e o empréstimo interbibliotecas (no caso de bibliotecas brasileiras) ou o envio de cópias xerox podem sanar diversas deficiências locais. Com o avanço da digitalização de documentos e do aumento do número de periódicos especializados que estão online e a disponibilização de diversas bases de dados para consulta, o trabalho de pesquisa tem se tornado cada vez mais possível, principalmente para os temas que, nós, historiadores da história das Américas, temos grandes dificuldades de acesso.

\section{A criação da home page da ANPHLAC}

Levando em consideração todas as questões relacionadas anteriormente, a criação da home page da ANPHLAC permitiu criar uma visibilidade que até então não existia para a nossa associação e nossa área de estudos. Naquele momento, tinha feito um curso de webdesign, e tinha aprendido os seus fundamentos, principalmente a linguagem HTML. Com os conhecimentos adquiridos, elaborei a página da ANPHLAC que continha, já naquele momento, diversas seções importantes.

Na página inicial, com textos também em espanhol, colocamos os objetivos da ANPHLAC, Associação Nacional de Pesquisadores de História Latino Americana e Caribenha, nome registrado à época:

A ANPHLAC se dedica ao estudo, à pesquisa e à divulgação de assuntos referentes à História da América Latina e Caribe. Seu surgimento aconteceu durante a década de 90, a partir da iniciativa de alguns profissionais da área, que preocupados com a marginalidade dos estudos latino-americanos na década de 80 , tiveram a certeza de que se fazia necessário tomar medidas concretas e urgentes. Neste sentido, um grupo de pesquisadores se encontrou em janeiro de 1992 em São Paulo, decidindo organizar, como primeiro passo, um Comitê que foi chamado de - "Comitê Nacional de Pesquisadores e Professores de História da América Latina e Caribe" (CONAPHLAC).

Em janeiro de 1993, o então CONAPHLAC organizou um encontro na Universidade de Ouro Preto, Campus de Mariana, já com a participação de um maior número de professores e pesquisadores representativos de grande parte das regiões brasileiras, quando foi decidido, por unanimidade, a criação 
de uma Associação Científica para tratar, exclusivamente, das questões pertinentes aos estudos e pesquisas latino-americanas. Foi, então, criada a "Associação Nacional de Pesquisadores de História Latino-Americana e Caribenha" - ANPHLAC.

Disponibilizamos também, na primeira página, naquele momento, o Documento de Mariana e o Estatuto da ANPHLAC. Nas demais páginas de conteúdo da home page da associação, foram colocadas informações sobre os membros da diretoria, as instruções e a ficha para a filiação, as notícias dos encontros da ANPHLAC já realizados, e o próximo encontro que seria realizado no ano 2000 em Salvador, BA, os boletins semestrais da ANPHLAC, além de links relacionados à História Latinoamericana.

\section{Os anais eletrônicos da ANPHLAC}

Outro marco importante foi a decisão tomada na Assembleia Geral da Associação Nacional de Pesquisadores de História Latino-americana e Caribenha (ANPHLAC), que se realizou em julho de 1999, durante o Encontro da ANPUH, em Florianópolis, em que ficou decidido que os Anais do III Encontro seriam eletrônicos. A partir desta decisão, empenhei-me no sentido de fazer todos os procedimentos e atividades necessários para a disponibilização online dos textos apresentados durante o Encontro, que foram entregues à comissão organizadora. Os anais eletrônicos do III Encontro da ANPHLAC foram disponibilizados em 1999 e, com isso, os textos acadêmicos apresentados podiam ser acessados por todos os interessados, aumentado a divulgação dos temas e pesquisas da área de História das Américas. Pela primeira vez, disponibilizamos na internet os trabalhos completos de nosso evento bianual.

\section{A criação do grupo de discussão da ANPHLAC}

Outra iniciativa importante foi a aprovação da criação de uma lista de discussão e de informação da ANPHLAC que teria como principal objetivo reunir os associados da ANPHLAC e interessados para que fosse possível a troca de informações sobre eventos científicos, publicações, endereços da web, intercâmbio de dados e notícias sobre investigações em curso na área de História das Américas. Fiz a proposta à assembleia da ANPHLAC em Salvador, no ano 2000, pois outro aspecto importante da 
internet era a possibilidade de participar de um grupo de discussão especializado que permitisse uma maior interação com a comunidade acadêmica nacional e internacional.

Em 9 de abril de 2001, criei, no Yahoo, a lista moderada de discussão da ANPHLAC com o objetivo de dedicar-se ao estudo, à pesquisa e à divulgação de assuntos referentes à História das Américas no endereço http://br.groups.yahoo.com/group/anphlac. A lista continua funcionando e para entrar nela é preciso fazer a inscrição na página do grupo de discussão ou enviar uma mensagem de e-mail para anphlac-subscribe@yahoogrupos.com.br. Atualmente, 11 anos depois, a lista continua cumprindo o seu papel de divulgação e interação em nossa comunidade. Temos, atualmente, na lista da ANPHLAC, 724 (setecentos e vinte e quatro) associados, e mais de 7.770 (sete mil setecentos e setenta) mensagens enviadas que podem ser consultadas e lidas. A lista é moderada e somente mensagens relacionadas ao estudo, à pesquisa e à divulgação de assuntos referentes à história da Américas são liberadas. Atualmente temos uma média de setenta mensagens mensalmente enviadas. A maioria das mensagens enviadas é informativa e de divulgação.

A criação da lista foi muito importante, pois antes de 2001 não tínhamos um espaço de divulgação próprio de assuntos referentes à história das Américas no Brasil. Neste longo período de existência a lista tem sido um veículo para a discussão de projetos, de dúvidas de pesquisa e de sugestões bibliográficas além, obviamente, das mensagens informativas e de divulgação de eventos, concursos públicos e lançamento de livros.

\section{O diretório de pesquisadores}

Conforme decisão dos associados em assembleia, decidimos disponibilizar também, em nossa home page, uma listagem dos pesquisadores em História das Américas que atuam no Brasil. Este Diretório, em que participam pesquisadores que trabalham com temas relacionados à História das Américas, tem como objetivo dar maior visibilidade aos pesquisadores da área de História das Américas. Este diretório pretende facilitar o intercâmbio entre os que pesquisam na área de História das Américas e divulgar para a comunidade em geral os pesquisadores que trabalham em nossa área de pesquisa. 


\section{Revista Eletrônica}

Outra iniciativa importante foi a criação da Revista Eletrônica da ANPHLAC no ano 2000. Esta revista, que passou a ser disponibilizada em nossa home page, é a publicação oficial da associação. A revista foi criada com o ISSN 1679-1061 e o seu primeiro número, referente ao ano de 2001, foi divulgado em nossa home page naquele mesmo ano, juntamente com a chamada de artigos para o segundo número, referente ao ano de 2002.

\section{Os trabalhos de webmaster, diagramação e otimização da página eletrônica}

Durante os anos iniciais de implementação dos mecanismos de divulgação da ANPHLAC na internet, cuidei dos aspectos práticos da criação da home page, da lista de discussão, dos anais eletrônicos e da revista eletrônica. Ou seja, assumi o papel de webmaster fazendo o site da ANPHLAC na linguagem html, a editoração $\mathrm{e}$ diagramação dos primeiros anais eletrônicos e dos números iniciais da revista, além de cuidar da administração e moderação da lista eletrônica da ANPHLAC. Foram momentos de muito trabalho, e muito gratificantes, pois foi um trabalho em prol de nossa associação que merece todo o nosso apoio e dedicação.

Como administrador da página eletrônica também tomei o cuidado de fazer a otimização da home page para que fosse rastreada pelas máquinas de busca na internet. Sabemos que um problema que tem se colocado com o avanço da internet é a infinidade de sites existentes, e se o pesquisador não está de posse do endereço eletrônico da instituição que deseja consultar, ele pode tentar o auxílio das máquinas de busca. Desde o ano de 2002, aproximadamente, uma pessoa que queira pesquisar assuntos referentes à história das Américas no Brasil, e coloque, por exemplo, as palavras - pesquisadores; história e América - nas principais máquinas de busca, encontrará entre os resultados, a referência à ANPHLAC em primeiro lugar ou entre os primeiros lugares.

\section{A aquisição de dominio próprio e construção da nova página da ANPHLAC}

Em 2006, ao assumir a presidência da ANPHLAC, fiz uma reformulação completa da home page da associação com a contratação de uma empresa especializada que elaborou, sob minha supervisão, a página eletrônica da ANPHLAC em modo 
dinâmico (flash) e em modo estático (html). Neste período, elaboramos a nova logomarca da ANPHLAC e fizemos o registo do CNPJ da associação, além de adquirirmos um domínio próprio, com o qual a home page da ANPHLAC passou a ser facilmente acessada - http://www.anphlac.org e também foram criados os e-mails fixos dos membros da diretoria, com o sufixo @anphlac.org. Também foi criado o e-mail institucional da Revista Eletrônica da ANPHLAC e foi registrado o prefixo editorial próprio da ANPHLAC na agência do ISBN.

Com o intuito de melhorar o processo de controle administrativo dos associados foi criada uma área de associados. Até 2006, os associados que quisessem se filiar precisavam fazer o download da ficha de inscrição no formato word no site da ANPHLAC, fazer o preenchimento da ficha em seu próprio computador e enviá-la por e-mail ao presidente ou tesoureiro da associação. Ao receber a ficha, os membros da diretoria da associação tinham que fazer o cadastro do associado manualmente copiando os dados recebidos da ficha de inscrição. A nova home page criada no final de 2006 modificou todo o processo. A partir de então, o controle dos associados passou a ser feito através do painel de controle da nova home page da ANPHLAC. Pessoas interessadas em participar da ANPHLAC passaram a se cadastrar no site mediante registro de login e senha. A partir de então, todo associado que se cadastrasse em nossa home page, poderia acessar os seus dados pessoais através de senha e atualizá-los. Os associados que mudassem o endereço, ou qualquer outra informação cadastral, poderiam fazer a alteração diretamente, o que facilitou imensamente o trabalho da secretaria. O trabalho de gestão da base de dados também foi agilizado permitindo o controle financeiro do pagamento de anuidades em um só lugar, sem ter que transferir dados e informações a cada mudança de diretoria. Os membros da diretoria da ANPHLAC tinham somente que conferir se o pagamento da anuidade foi feito e mudar o status da pessoa para associada e marcar o ano correspondente à anuidade paga. Uma forte preocupação da ANPHLAC foi sempre ter, entre seus integrantes, e associados, historiadores comprometidos com o fortalecimento da área de História das Américas. A ANPHLAC tem estimulado também a renovação em seus quadros, abrindo-se para a nova geração de pesquisadores, fato que pode ser constatado através da campanha de filiação em nossa home page e a realização de nosso recadastramento de associados durante o ano de 2007. Isto permitiu a renovação e atualização de nossa base de 
associados visto que nossa base de dados anterior tinha muitos nomes com endereços desatualizados.

Houve também vários outros melhoramentos no painel de controle, o que facilitou o controle e permitiu que a diretoria, que assumiu posteriormente, tivesse acesso aos dados dos associados imediatamente. Através da nova home page, os membros da diretoria passaram a poder gerar e imprimir listas de associados quites com a anuidade de qualquer ano ou listas de não-associados, podiam gerar etiquetas para o envio de mala direta, e, ainda, podiam gerar a lista de e-mails de associados ou não associados para envio de mensagens eletrônicas específicas para cada segmento. Além dessas melhorias, também foram reformulados os projetos gráficos do Boletim Eletrônico e da Revista Eletrônica naquele momento.

E, finalmente, também foi criado um sistema que permitiu a colocação de notícias e links e várias outras informações sem que fosse necessário ter conhecimentos técnicos específicos. Os membros da diretoria passaram a poder elaborar notícias e informações para os associados e atualizar várias seções da home page, usando um programa comum de edição de textos, como o Word ou OpenOffice e, através do copiar/colar, transferi-los imediatamente para a home page sem complicações.

\section{Disponibilização do material de apoio didático ao ensino de História das Américas}

Outro etapa importante no processo de divulgação de conteúdos em nossa home page foi a decisão de nossos associados em assembleia de criar e, logo depois, reformular o Grupo de Trabalho da associação que passou a ser chamado de GT Ensino de História das Américas e Fontes. Dentre suas funções, podemos destacar a de divulgação de materiais didáticos de História das Américas que sirvam de apoio ao professor de História dos ensinos fundamental e médio, produzidos e organizados, de modo voluntário e gratuito, por especialistas nos temas disponibilizados.

Diversos materiais foram disponibilizados, a partir de 2007, com a feitura do módulo de conteúdo do GT acoplado à home page e os conteúdos foram divididos em três blocos temáticos: América Pré-colonial/Indígena; América Colonial e América Independente.

\section{Nova reformulação da página eletrônica da ANPHLAC}


O projeto gráfico da home page da ANPHLAC criado no período 2006/2007 ficou no ar até o final do ano de 2010. Neste ano tivemos de contratar uma nova empresa para cuidar de nossa home page, visto que os responsáveis pela empresa anterior resolveram encerrar suas atividades devido a novos projetos e viagens de estudos. Com a nova contratação foi realizado um novo projeto gráfico que tentou manter os aspectos positivos da home page anterior e aprimorar outros pontos. O novo visual da home page da ANPHLAC entrou no ar durante o ano de 2011. Foi um período de grande trabalho, pois como supervisor do processo de migração dos dados, para evitar atrasos, acabei tendo que me envolver mais diretamente e fiz, inclusive, a digitação de todos os dados referentes aos conteúdos do módulo do GT para a nova base de dados. Todo o processo de migração é trabalhoso e durante o ano de 2011 esta foi uma de nossas maiores preocupações. Finalmente, no final de 2011, a nova home page estava com todos os principais módulos em funcionamento divulgando os conteúdos da ANPHLAC e fazendo a divulgação do X Encontro Internacional da ANPHLAC, que ocorreria em São Paulo, em julho de 2012.

\section{Implantação do sistema eletrônico de editoração de revistas}

O sistema eletrônico de Editoração de Revistas (SEER) adotado pelo IBICT, que utiliza a plataforma do Open Jounal Systems (OJS), é um software para a gestão de periódicos eletrônicos, recomendado pela CAPES, que permite um controle completo online do processo de submissão, análise, revisão e publicação de artigos.

Este software foi implantado no servidor que hospeda a home page da ANPHLAC em meados de 2011. Como não tínhamos ainda um profundo conhecimento do uso do sistema SEER, fiz um estudo dos manuais de uso do referido sistema para incluir dois números referentes ao ano de 2011 da Revista Eletrônica da ANPHLAC, que me foram repassados pelo Conselho Editorial da Revista em sua versão final revisada; ou seja, a Revista Eletrônica da ANPHLAC passou a usar o novo sistema a partir de 2011.

A home page da ANPHLAC, ao direcionar o leitor para a página da revista, permite agora que os autores realizem o seu cadastro eletronicamente, façam a submissão de seus artigos e acompanhem o andamento da avaliação dos artigos submetidos. Também os leitores podem se cadastrar e assinar para receber notícias 
publicadas pelos editores. Além disso, todos os cadastrados podem consultar os números publicados, usar mecanismos internos de pesquisa e procura. O processo de migração dos números anteriores a 2011 está em andamento, sob a responsabilidade do Conselho Editorial da Revista.

\section{Conclusão}

Hoje em dia, a home page da Associação Nacional de Pesquisadores e Professores de História das Américas (ANPHLAC) é um grande e importante repositório de dados para os pesquisadores e professores da área de História das Américas no Brasil. Este banco de dados está indexado nas principais máquinas de busca e pode ser facilmente acessado por todas as pessoas interessadas nos temas da área de História das Américas.

Nossa home page disponibiliza, conforme vimos neste artigo, uma série de materiais. Dentre eles, destacamos os Anais Eletrônicos do III Encontro em São Paulo, do IV Encontro em Salvador, do V Encontro em Belo Horizonte, do VI Encontro em Maringá, do VII Encontro em Campinas, do VIII Encontro em Vitória e do IX Encontro em Goiânia. Dentro em breve estarão disponibilizados os Anais Eletrônicos do X Encontro em São Paulo. Também estão disponibilizados 11 números de nossa Revista Eletrônica. Dentro em breve estarão disponibilizados os números 12 e 13 referentes ao ano de 2012. Também não podemos esquecer os materiais didáticos disponibilizados.

Podemos constatar que a home page da ANPHLAC, nos relatórios estatísticos de acesso ao site, tem tido um grande número de acessos, inclusive muitos acessos de outros países. Se no início dos anos de 1990 a ANPHLAC foi criada pelos profissionais da área porque estavam "preocupados com a marginalidade dos estudos latinoamericanos na década de 1980" no Brasil, a partir de diversos fatores, sendo um deles o uso, pela ANPHLAC, da internet para o desenvolvimento e divulgação dos estudos sobre a História das Américas no Brasil, temos hoje uma maior visibilidade que gera novas perspectivas e potencialidades aos trabalhos e pesquisas feitos pela área no Brasil.

Nossa associação e nossos encontros congregam hoje um grande número de pesquisadores e demonstra o fortalecimento crescente da ANPHLAC. Podemos considerar, hoje, que nosso Encontro Internacional é o maior evento de historiadores brasileiros que pesquisam na área de História das Américas, como demonstram a 
quantidade de inscritos e o número de mesas redondas. Sem dúvida, a visibilidade de nossa página e o uso intensivo dos meios eletrônicos de divulgação têm sido um dos fatores que tem contribuído para este crescimento. Provenientes de diversas regiões do país e também do exterior, os trabalhos inscritos têm nos apresentado os resultados de pesquisas e têm debatido variados temas diretamente relacionados à História das Américas. Uma rica e complexa rede de relações individuais e interinstitucionais têm se estabelecido, favorecendo a riqueza e a variedade de intercâmbios intelectuais.

Conforme nossa percepção, desde o final dos anos de 1990, as novas tecnologias existem, estão aí, e não podemos prescindir de seu uso. $\mathrm{O}$ uso da home page e a disponibilização dos conteúdos produzidos pela ANPHLAC se mostrou extremamente importante. Temos que aprimorar este veículo de divulgação e mantê-lo, cada vez mais, como um de nossos meios mais privilegiados para a o estímulo das pesquisas e divulgação da História das Américas feita no Brasil. 